Western University

Scholarship@Western

Department of Economics Research Reports

Economics Working Papers Archive

1989

\title{
Resource Discoveries and "Excessive" External Borrowing
}

Arman Mansoorian

Follow this and additional works at: https://ir.lib.uwo.ca/economicsresrpt

Part of the Economics Commons

Citation of this paper:

Mansoorian, Arman. "Resource Discoveries and "Excessive" External Borrowing." Department of Economics Research Reports, 8912. London, ON: Department of Economics, University of Western Ontario (1989). 
ISSN : 0318-725X

ISBN : 0-7714-1148-0

RESEARCH REPORT 8912

RESOURCE DISCOVERIES AND "EXCESSIVE"

EXTERNAL BORROWING

by

Arman Mansoorian

Department of Economics

University of Western Ontario

London, Ontario, Canada

N6A $5 C 2$

JAM 1 S 9990 


\title{
RESOURCE DISCOVERIES AND "EXCESSIVE" EXTERNAL BORROWING
}

\author{
By Arman Mansoorian \\ Department of Economics, \\ Social Science Centre, \\ University of Western Ontario, \\ London, Ontario, \\ Canada, N5A 5C2.
}

\begin{abstract}
Well known three sector models from the Dutch Disease literature are incorporated into the overlapping generations framework of Blanchard (1985), and it is shown that if the extraction of natural resources is capital intensive, then a resource discovery may shift income away from labour. If this happens then the asset holders at the time of the discovery will incur such a large debt that, in order to pay the interest on the debt, aggregate expenditure in the new steady state would have to be smaller than it was originally. The country may then experience both real depreciation and pro-industrialisation.
\end{abstract}

I would like to thank Michael Devereux for very helpful comments and discussions, and the Social Sciences and Humanities Research Council of Canada for financial support. All errors are mine alone. 
Table of Contents

I. Introduction

II. The Model

III. The effects of a resource discovery

IV. Conclusions

Appendix 1

Appendix 2. The Benchmark Model

References 


\section{Introduction}

In the 1970's a number of developing countries accumulated huge debts, following their discoveries of natural resources. Prominent among these were Mexico and Venezuela. The amount of debt incurred by these countries is so large that they are forced to undergo austerity measures in order to be able to pay the interest on their debts. In particular, most of the amount borrowed by Mexico went into consumption or short term investment projects. ${ }^{1}$ Therefore, in this paper such heavy borrowing is viewed as an intergenerational problem. Well known models from the Dutch Disease (DD) literature are incorporated into the overlapping generations (OLG) framework of Blanchard (1985). Without intergenerational altruism, all the discovered resources are consumed by the generations alive at the time of the discovery, who borrow against all future incomes from these resources. In addition to this, if the extraction of the new resources leads to a shift in income from labour to non-human factors, there will be windfall gains to the generations holding non-human assets. Thus, in the short run after the resource discovery, there will be a sharp increase in aggregate expenditure, part of which will fall on non-traded goods, as the generations alive at the time of the discovery try to consume all the discovered resources and the windfall gains to non-human factors. In the short run the country will very likely experience both real appreciation and de-industrialisation, as in standard DD models. Over time, however, as the discovered resources and the windfall gains to non-human factors are consumed, the country's net foreign asset position will deteriorate and aggregate expenditure will fall, untill in the long run aggregate expenditure will be smaller than it was originally. ${ }^{2}$ The country may then experience both real depreciation and pro-industrialisation.

A number of papers in the DD literature have used Keynesian or neo-Keynesian fixed-price models in order to draw attention to the short term adjustment problems which may result from

1 See, for example, Harberger (1985).

2 Note that Fried (1980) incorporates the Heckscher-Ohlin model into Diamond's (1965) OLG framework. He shows if there is a labour saving technical progress then the asset holders alive at the time of the progress will gain and everyone else will lose, which is rather similar to our result. However, here we have a three sector model with non-traded goods, which allows us to discuss the long run implications of a resource discovery in a model akin to those in the DD literature. (Also, see footnote 3 below) 
a resource discovery due to price rigidities. Prominent among these are Buiter and Purvis (1983), Eastwood and Venables (1982), Neary and van Wijnbergen (1984), and van Wijnbergen (1984b). For example, Neary and van Wijnbergen (1984) extend the exchange rate overshooting model of Dornbusch (1976) by assuming that consumption and the demand for money depend on wealth. They also assume that the resource sector is completely independent of the rest of the economy, so that a resource discovery represents an increase in wealth without any supply effects. Thus, after a resource discovery there will be an increase in desired consumption, which will tend to put inflationary pressures on the economy. The increase in wealth will also increase the demand for money, which will tend to put deflationary pressures on the economy. With sticky prices, if the demand for money rises by a sufficiently large amount the resource discovery may lead to a recession in the short run.

Less attention has been given to the long term problems that a resource discovery may lead to. van Wijnbergen (1984a) draws attention to one such long term problem. van Wijnbergen (1984a) has a three sector model in which the resource sector is completely independent of the rest of the economy. A resource discovery has the effect of increasing wealth and the consumption of the non-traded good, which leads to a real appreciation and contraction of the manufacturing sector. This de-industrialisation may then lead to a loss in learning-by-doing in the manufacturing sector, which may then lead to long term problems. The present paper draws attention to another long term problem; the possibility of large scale borrowing by the generation alive at the time of the resource discovery leaving a burden for future generations.

In a recent paper, Eaton (1987) arrives at a similar conclusion to ours concerning the effects of a resource discovery on the welfare of future generations. Eaton (1987) incorporates the specific factors model of Jones (1971) into the OLG framework of Diamond (1965). Land and capital are then viewed as means of transferring purchasing power over time. Land is a fixed factor, while capital is accumulable. However, there is no external borrowing and no non-traded sector. In that model if there is an increase in the supply of land then there will be too many assets in the economy to carry savings over time. Thus, there will be a classic type of crowding out of capital, which may lead to a fall in the steady state real wage and make future generations worse off. Our result, on the other hand, comes about because, following a resource discovery, the country experiences a sharp deterioration in its net foreign asset position, which reduces the 
country's aggregate expenditure, the price of the non-traded good, and the wage rate. This sharp deterioration in the net foreign asset position of some developing countries is one of the most serious problems currently facing these countries. ${ }^{3}$

By incorporating well known three sector models from the DD literature into Blanchard's OLG framework, we are also able to compare our results with those of traditional DD models. In the simplest DD model the resource sector is completely independent of the rest of the economy. A resource discovery by increasing wealth and the demand for the non-traded good, unambiguously causes a real appreciation and de-industrialisation, as in van Wijnbergen (1984a), described above. This, however, need not be the case if the resource sector is an integral part of the rest of the economy. For example, in Corden and Neary (1982, Section III) the extraction of the new resources requires the kind of factors used more intensively used in the non-traded sector relative to the manufacturing sector. This means that the extraction of the new resources will encourage production in the manufacturing sector. Thus, if the demand for the non-traded good does not rise by a large amount then the country will experience pro-industrialisation and real appreciation. In Neary and Purvis (1983), on the other hand, the extraction of the new resources requires the kind of factors used more intensively in the manufacturing sector. Thus, a resource discovery in that case will cause de-industrialisation and real depreciation provided the demand for the non-traded good does not increase by a large amount. However, as pointed out by Neary and van Wijnbergen (1986, footnote 24), traditional DD models cannot predict the possibility of both real depreciation and pro-industrialisation. This, however, is a possible long run outcome in our model. As argued above, a resource discovery will lead to a short run real appreciation and de-industrialisation. However, over time, as the discovered resources are consumed, the price of the non-traded good will fall and the output of the manufacturing sector will rise. If the resource

3 Note that for our purpose the OLG framework of Blanchard has a distinct advantage over Diamond's for the following reason. In Blanchard's framework agents have uncertain lifetimes and there are life insurance companies that take over agents' assets upon their death. This means that agents can leave debt behind through life insurance companies. The country's net foreign asset position at any point in time is then a predetermined variable, and we can regard the country as having inherited debt from previous generations. In Diamond's model, on the other hand, agents have certain lifetimes and they pay off all their debts before they die. This means that we can no longer regard the country as having inherited debt from previous generations the way we could in Blanchard's framework, even though both frameworks give us similar results. As our main argument is that the current debt problems of some developing countries is that they have inherited it from previous generations, Blanchard's framework is better suited for our purpose. 
sector is capital intensive, then in the long run aggregate expenditure will be smaller than it was originally. Thus, in the long run the country could experience both real depreciation and proindustrialisation.

The paper is organised as follows. The model is presented in Section II. The effects of a resource discovery are discussed in Section III. Some concluding remarks are made in Section IV.

\section{The Model}

The household side of the model is a two good variant of Blanchard's (1985) model. Time is continuous, and at any instant a large cohort, whose size is normalised to $\pi$, is born. $\pi$ is the constant probability of death that agents face throughout their lives. As $\pi$ is constant, the expected remaining life of an agent of any age is given by $\int_{0}^{\infty} t e^{-s t} d t=\pi^{-1}$, and a cohort born at time zero has a size, as of time $t$, of $\pi e^{-x t}$. Thus, the size of the population at any time $t$ is $\int_{-\infty}^{t} \pi e^{-\pi(1-s)} d s=1$. We assume that agents are endowed with $L$ units of labour, which they supply throughout their lives. As we have normalised the size of the population to unity, the supply of labour in the economy at any moment in time is $\mathrm{L}$.

We assume that there is no bequest motive and that negative bequests are prohibited. As large numbers of agents are born at any instant, we follow Blanchard and assume that there will be life insurance companies which will contract to take over agents' wealth (positive or negative) upon their death in return for a fee. Perfect competition and free entry will ensure that the life insurance contracts that are offered are actuarially fair. As agents leave no human wealth on their death, this means that agents with non-human wealth $a(t)$ at time $t$ will contract to recieve $\pi a(t)$ if they do not die, and to leave $a(t)$ if they die.

The model has two final consumption goods, called non-traded and manufacturing. There and three sectors in the economy: a non-traded sector, a manufacturing sector, and a resource sector. The output of the resource sector is simply exported. The production side of the model can be very general, as we will be using GDP functions. However as a benchmark case we will specify a variant of the production structure used by Neary and Purvis (1983). Our main results will not depend on this assumption. The only difference between the production structure used in the benchmark case here and in Neary and Purvis is that here the non-traded sector uses a 
factor that is specific to it. As we will see in the next section, this assumption is not critical to our results. It simply has the effect of making the number of factors used exceed the number of goods produced. This then means that in addition to the redistribution of income among factors of production brought about by changes in the price of the non-traded good, a resource discovery redistributes income among factors of production at constant goods prices. As the main thrust of our argument is that a resource discovery can lead to large scale borrowing if it shifts income away from labour and towards non-human factors, the inclusion of this additional channel is deemed necessary, although inessential.

The output of the non-traded sector at time $t\left(X_{N}(t)\right)$ is given by

$$
X_{N}(t)=F^{N}\left(L_{N}(t), T\right)
$$

where $L_{N}(t)$ is the input of labour in that sector at time $t$, and $T$ is the country's endowment of the factor specific to the non-traded sector. $F^{N}($.$) is a constant returns to scale production func-$ tion.

The output of the manufacturing sector at time $t\left(X_{M}(t)\right)$ is given by

$$
X_{M}(t)=F^{M}\left(L_{M}(t), K_{M}(t)\right)
$$

where $L_{M}(t)$ is the input of labour into the manufacturing sector at time $t, K_{M}(t)$ is the amount of capital used in manufacturing at time $t$, and $\mathrm{F}^{\mathrm{M}}(\mathrm{.})$ is a linear homogeneous production function.

The country is endowed with $R$ wells. Only capital is used in the extraction of the resources, and the output of that sector at time $t$ is given by

$$
X_{R}(t)=F^{R}\left(R, K_{R}(t)\right),
$$

where $K_{R}(t)$ is the amount of capital used in the resource sector at time $t$, and $F^{R}($.$) is a constant$ returns to scale production function.

Note that the non-traded and manufacturing sectors form a miniature specific factors model (henceforth referred to as $\mathrm{SFM}_{\mathrm{NM}}$ ), where the mobile factor is labour and the fixed factors are $T$ and $K_{M}$. Similarly, the resource and manufacturing sectors form a miniature specific factors model (henceforth referred to as $S F M_{R M}$ ), where $K$ is the mobile factor while $R$ and $L_{M}$ are the fixed factors. Thus, the production side of the economy consists of two miniature specific factors 
models which are connected by the manufacturing sector. The properties of this production structure are studied in Appendix 2. We take these as given in the main text of the paper.

At any time $t$ the value of the country's gross domestic product is given by $g(t)=g\left(p_{N}(t), p_{M}(t), p_{R}(t), L, K, R, T\right)$, where $p_{j}(t)(j=N, M, R)$ is the price of the output of sector $\mathrm{j}$ at time t. As $p_{M}$ and $p_{R}$ are given internationally, we set them equal to unity.

There are four types of assets in the economy. There are titles to each non-human factor in the economy $(T, K$, and $R)$. There are, also, internationally traded bonds, whose price is fixed at unity in terms of the numeraire good, and which have a fixed rate of return of $r^{*}$. We assume that the titles to the country's factors are in fixed supply, and are not internationally traded, but that agents can issue bonds and sell them abroad if they wish. ${ }^{4}$

Let $q_{i}(t)(i=K, T, R)$ be the price of a title to a unit of factor $i$ at time $t$, and $g_{i}$ the partial derivative of the GDP function with respect to argument $i$. Then, as bonds and titles to nonhuman factors are perfect substitutes, the arbitrage condition

$$
\dot{\mathrm{q}}_{\mathrm{i}}(\mathrm{t})=\dot{\mathrm{r}}^{*} \mathrm{q}_{\mathrm{i}}(\mathrm{t})-\mathrm{g}_{\mathrm{i}}(\mathrm{t}) \quad(\mathrm{i}=\mathrm{K}, \mathrm{T}, \mathrm{R})
$$

ensures that agents cannot make profits or losses by selling their titles to any factor $i$, investing the proceeds in bonds, and using the returns on the bonds to rebuy the titles an instant later. 5

(1) then implies that $\int_{t}^{\infty} \dot{q}_{i}(v) e^{-\int_{t}^{v} v^{*} d u} d v=\int_{t}^{\infty}\left[r^{*} q_{i}(v)-g_{i}(v)\right] e^{-\int_{t}^{v} r^{*} d x} d v$, which gives

$$
q_{i}(t)=\int_{t}^{\infty} g_{i}(v) e^{-\int_{i}^{v} \cdot d \mu} d v \quad(i=K, T, R)
$$

Note that the value of a title to a unit of the non-human factor $i$ is the present value of the returns to that factor, where future returns are discounted at the market rate of interest. This means that

4 We do not allow for capital accumulation. However, our main results would go through, and not much additional insight would be gained, if we did allowed for capital accumulation subject to adjustment costs, as in Matsuyama (1988). Matsuyama incorporates the Heckscher-Ohlin model into Diamond's OLG framework and considers the effects of a terms of trade change on the current account. He shows that his results are essentially left unchanged if the capital stock is allowed to change subject to adjustment costs.

5 Note that by the properties of the GDP function $g_{i}(t)$ is the return to factor $i$ at time $t$. 
even though agents holding the titles to the country's non-human factors have finite planning horizons, they bear all the benefits (costs) born by these factors due to a shock into the infinite future. Thus, if the resource sector is an enclave, so that a resource discovery is like a transfer from abroad, then during the adjustment period to the new steady state the country will accumulate debt the interest on which will be equal to the income from the discovered resources: the country will, in effect, have consumed all the discovered resources. Moreover, if the resource sector is not an enclave and the extraction of the new resources increases the return to nonhuman factors, then the intrest on the debt accumulated during the adjustment period to the new steady state will be larger than the income from the discovered resources.

Let $C_{N}(s, v)$ and $C_{M}(s, v)$ denote the consumptions of non-traded and manufactured goods by an agent born at time $s$, as of time $v$. Then, if we assume that the instantaneous utility function is logarithmic, the agent's objective function at time $t$ will be

$$
E_{\mathrm{t}}\left[\int_{\mathrm{t}}^{\infty}\left[\alpha \log C_{N}(s, v)+(1-\alpha) \log C_{M}(s, v)\right] e^{\theta(t-v)} d v\right], \quad \theta \geq 0
$$

With constant $\pi$, this reduces to

$$
\int_{t}^{\infty}\left[\alpha \log C_{N}(s, v)+(1-\alpha) \log C_{M}(s, v)\right] e^{(\pi+\theta)(t-v)} d v
$$

Now let $a(s, t)$ be the total financial wealth of the same individual at time $t, b(s, t)$ his net bond holdings, and $\rho_{1}(s, t)$ the number of his titles to factor $i$. Then we will have $a(s, t)=b(s, t)+\sum_{i} q_{1}(t) \rho_{i}(s, t)$, and the dynamic budget constraint of the agent will be

$$
\begin{gathered}
\dot{a}(s, t)=\pi\left[b(s, t)+\sum_{i} q_{i}(t) \rho_{i}(s, t)\right]+\sum_{i} \dot{q}_{i}(t) \rho_{i}(s, t)+r b(s, t)+\sum_{i} g_{i}(t) \rho_{i}(s, t) \\
+g_{L}(t) L-p_{N}(t) C_{N}(s, t)-C_{M}(s, t),
\end{gathered}
$$

which is obtained as follows. If the agent has $b(s, t)$ number of bonds and titles to $\rho_{1}(s, t)$ units of the non-human factor $i(i=K, T, R)$, then he will recieve $\pi\left[b(s, t)+\sum_{i} q_{1}(t) \rho_{1}(s, t)\right]$ from the insurance company, an interest of $r^{*} b(s, t)$ on his bonds, and an income of $\underset{i}{\Sigma} g_{1}(t) \rho_{i}(s, t)$ from his nonhuman factors. He will also have a labour income of $g_{L}(t) L$, and capital gains of $\Sigma \dot{q}_{1}(t) p_{1}(s, t)$. The 
change in his wealth at time $t$ will then be this total income less his expenditure at time $t$ $\left(p_{N}(t) C_{N}(s, t)+C_{M}(s, t)\right)$, which is given by the right hand side of $(4)$.

In addition to (4), the agent has to satisfy the transversality condition

$$
\lim _{v \rightarrow \infty} e^{-\int_{t}^{v}\left(r^{*+\pi}\right) d u} a(s, v)=0
$$

which ensures that he does not go on borrowing without bound.

If we use (1) and the fact that $a(s, t)=b(s, t)+\sum_{i} q_{1}(t) \rho_{i}(s, t)$, then we can write (4) as

$$
\dot{a}(s, t)=\left(r^{*}+\pi\right) a(s, t)+g_{L}(t) L-p_{N}(t) C_{N}(s, t)-C_{M}(s, t)
$$

(5) and (6) then imply that we can write the agent's budget constraint as

$$
\int_{t}^{\infty}\left[p_{N}(v) C_{N}(s, v)+C_{M}(s, v)\right] e^{-\int_{1}^{\infty}(r+\pi) d \mu} d v=h(s, t)+a(s, t)
$$

where $h(s, t)$ is the agent's human wealth at time $t$ and is given by

$$
h(s, t)=\int_{t}^{\infty} g_{L}(v) L e^{-\int_{1}^{v}\left(r^{\cdot}+\pi\right) d \mu} d v
$$

The agent's problem then is to maximize (3) subject to (7) by choosing an optimal sequence of consumption levels. This optimization problem could be done in two stages. In the first stage the agent decides how much of each good to consume at any given time $t$ for a given level of expenditure, $z(s, t)$. In the second stage he decides how to spread his total wealth on consumption over his lifetime.

From the first stage of the agent's problem we can obtain the indirect utility function $V\left[p_{N}(t), z(s, t)\right]$. As the instantaneous utility function is logarithmic, this indirect utility function is given by

$$
V[p(t), z(s, t)]=\Omega-\alpha \log p_{N}(t)+\log z(s, t)
$$


where $\Omega=\alpha \log \alpha+(1-\alpha) \log (1-\alpha)$. The second stage of the agent's problem could then be written as

$$
\begin{aligned}
& \max _{z(s, v)} \int_{t}^{\infty}\left[\Omega+\alpha \log p_{N}(v)+\log z(s, v)\right] e^{-\int_{t}^{v}(\pi+\theta) d \mu} d v \\
& \text { s.t. } \int_{t}^{\infty} z(s, v) e^{-\int_{1}^{v}\left(r^{\prime}+\pi\right) d \mu} d v=h(s, t)+a(s, t) .
\end{aligned}
$$

It is then easy to show that this programme gives

$$
z(s, t)=(\pi+\theta)[a(s, t)+h(s, t)]
$$

In order to get the aggregate expenditure in the economy, $Z(t)$, multiply (9) by the size of the cohort born at time $s$ (that is, by $\left.\pi \mathrm{e}^{\mathrm{s}(\mathrm{t}-\mathrm{s})}\right)$, and integrate over $\mathrm{s}$ to get

$$
Z(t)=(\pi+\theta)[A(t)+H(t)]
$$

where $A(t)\left(=\int_{-\infty}^{t} a(s, t) \pi e^{z(t-s)} d s\right)$ and $H(t)\left(=\int_{-\infty}^{t} h(s, t) \pi e^{z(t-s)} d s\right)$ represent aggregate financial and human wealth at time $t$, respectively. Note that

$$
A(t)=B(t)+q_{K}(t) K+q_{R}(t) R+q_{T}(t) T,
$$

where $B(t)$ is the net foreign asset position of the economy. Moreover,

$$
\dot{A}(t)=\pi \mathrm{a}(\mathrm{t}, \mathrm{t})-\pi \mathrm{A}(\mathrm{t})+\int_{-\infty}^{\mathrm{t}} \dot{\mathrm{a}}(\mathrm{s}, \mathrm{t}) \pi \mathrm{e}^{\pi(\mathrm{t}-\mathrm{s})} \mathrm{ds}
$$

where $\pi \mathrm{a}(\mathrm{t}, \mathrm{t})$ is the financial wealth of the newly born, which is equal to zero, $\pi \mathrm{A}(\mathrm{t})$ is the wealth of those who die, and $\int_{-\infty}^{t} \dot{a}(s, t) \pi \mathrm{e}^{\pi(t-s)} d s$ is the change in the financial wealth of those who stay alive.

Using (4) in (11), and the fact that the GDP function is homogeneous of degree one in the country's factor endowments, we can show that

$$
\dot{A}(t)=\dot{r} B(t)+g(t)+\dot{q}_{K}(t) K+\dot{q}_{T}(t) T+\dot{q}_{R}(t) R-Z(t) .
$$


Now note that $\dot{A}(t)=\dot{B}(t)+\dot{q}_{K}(t) K+\dot{q}_{T}(t) T+\dot{q}_{R}(t) R$, which means that (12) can be written as

$$
\dot{B}(t)=\dot{r}^{*} B(t)+g(t)-Z(t)
$$

Thus, the country will accumulate bonds if national income is greater than aggregate expenditure.

Now, note that the evolution of aggregate human wealth is given by

$$
\begin{aligned}
\dot{H}(t) & =\frac{d}{d t}\left[\int_{-\infty}^{t}\left[\int_{t}^{\infty} g_{L}(v) L e^{-\int_{t}^{v}\left(r^{*}+\pi\right) d \mu} d v\right] \pi e^{\pi(s-t)} d s\right] \\
& =-g_{L}(t) L+\left(r^{*}+\pi\right) H(t) .
\end{aligned}
$$

Now, from (10) we have

$$
\dot{Z}(t)=(\pi+\theta)[\dot{A}(t)+\dot{H}(t)]
$$

Thus, substituting for $\dot{A}(t)$ and $\dot{H}(t)$ from (12) and (14) into (15) and using (1), we can show that

$$
\dot{Z}(t)=\left(r^{*}-\theta\right) Z(t)-\beta\left[B(t)+q_{K}(t) K+q_{T}(t) T+q_{R}(t) R\right]
$$

where $\beta=\pi(\pi+\theta)$.

The evolution of the system is described by equations (1), (13), and (16). In addition, the non-traded goods sector should clear at all t. As the instantaneous utility function is logarithmic, agents will spend a proportion $\alpha$ of $Z(t)$ on the non-traded good at time $t$. Thus, the demand for non-traded goods at time $t$ is $\frac{\alpha Z(t)}{P_{N}(t)}$. This should be equal to the supply of non-traded goods at time $t, g_{p N}(t)$. Thus, we should have

$$
\frac{\alpha Z(t)}{P_{N}(t)}=g_{p_{N}}(t) \forall t
$$

Note that this market satisfies the (static) Walrasian stability condition, as the excess demand function is decreasing in $p_{N}$. Thus, we can solve for $p_{N}(t)$ in terms of $Z(t), L, K, T$, and $R$ and write,

$$
p_{N}(t)=\Phi(Z(t), L, K, T, R) \quad \text { with } \Phi_{Z}>0 \text { and } \Phi_{R}<0
$$


This is shown in Appendix 2 for the Benchmark model. The reason for $\Phi_{R}$ being negative is as follows. An increase in $R$ means that the resource sector will draw capital from the manufacturing sector. This will release labour for the non-traded sector. Thus, the output of the nontraded sector will rise, which will tend to reduce $p_{N}(t)$.

Substituting for $p_{N}(t)$ from (17) into (1), (13), and (16), we can write the complete dynamics of the system as

$$
\begin{aligned}
& \dot{B}(t)=\dot{r}^{*} B(t)+g(\Phi(t), L, K, R, T)-Z(t), \\
& \dot{Z}(t)=\left(\dot{r}^{*}-\theta\right) Z(t)-\beta\left[B(t)+q_{R}(t) R+q_{K}(t) K+q_{T}(t) T\right], \text { and } \\
& \dot{q}_{i}(t)=\dot{r} q_{i}(t)-g_{i}(\Phi(t), L, K, R, T), \quad(i=R, K, T) .
\end{aligned}
$$

Linearising these equations around the steady state, we get

$$
\begin{aligned}
& \dot{y}(t)=Q(y(t)-\bar{y}), \\
& \text { where } y(t)=\left[\begin{array}{c}
B(t) \\
Z(t) \\
q_{R}(t) \\
q_{K}(t) \\
q_{T}(t)
\end{array}\right] \text {, and } Q=\left[\begin{array}{ccccc}
r^{*} & g_{p_{N}} \Phi_{Z}-1 & 0 & 0 & 0 \\
-\beta & r-\theta & -\beta R & -\beta K & -\beta T \\
0 & -g_{R p_{N}} \Phi_{Z} & r & 0 & 0 \\
0 & -g_{K p_{N}} \Phi_{Z} & 0 & r^{*} & 0 \\
0 & -g_{T_{p_{N}}} \Phi_{Z} & 0 & 0 & r^{*}
\end{array}\right] \text { Also, } \bar{y} \text { is the }
\end{aligned}
$$

steady state level of $y$. Now B is the only predetermined variable in this system. $Z, q_{R}, q_{K}$ and $q_{T}$ are all jump variables. Thus, the model is saddle point stable if $\mathbf{Q}$ has four positive and one negative eigenvalues. In Appendix 1 we show that this condition is satisfied. This saddle point stability condition implies that the determinant of $\mathbf{Q}$ is negative. Moreover, if $\zeta$ is the negative eigenvalue of $\mathbf{Q}$ then the unique convergent path of the model to the new steady state will be given by

$$
\begin{aligned}
& B(t)-\bar{B}=\left(B_{0}-\bar{B}\right) e^{\zeta t}, \\
& Z(t)-\bar{Z}=\left(B_{0}-\bar{B}\right) \frac{\left(r^{-}-\zeta\right)}{\left(1-g_{p_{N}} \Phi_{Z}\right)} e^{\zeta t}, \text { and } \\
& q_{i}(t)-\bar{q}_{i}=\left(B_{0}-\bar{B}\right) \frac{\left(g_{i} p_{N} \Phi_{Z}\right)}{\left(1-g_{p_{N}} \Phi_{Z}\right)} e^{\zeta t} \quad(i=K, R, T),
\end{aligned}
$$


where $B_{0}$ is the country's initial net holdings of bonds.

Note that, from (17), $\Phi_{Z}=\frac{\alpha}{g_{P_{N}}+p_{N} g_{P_{N P N}}}$. Thus, $\left(1-g_{P_{N}} \Phi_{Z}\right)>0$. Therefore, during the adjustment period to the new steady state aggregate expenditure and the country's net foreign asset position move in the same direction. The reason for this is that a deterioration in the country's net foreign asset position requires a reduction in aggregate expenditure in order for the country to be able to pay the interest on the increased debt.

\section{The Effects of a Resource Discovery}

In this section we consider the effects of a resource discovery. Here we use GDP functions and give intuitive explanation for our results with reference to the Benchmark model. In Appendix 2 we derive the results for the Benchmark model.

Note that in the long run we should have $\dot{B}=\dot{Z}=\dot{q}_{R}=\dot{q}_{k}=\dot{q}_{r}=0$, which, from (18) implies,

$$
\begin{aligned}
& 0=r^{*} \bar{B}+\bar{g}-\bar{Z}, \\
& 0=\left(r^{*}-\theta\right) \bar{Z}-\beta\left[\bar{B}+\bar{q}_{R} R+\bar{q}_{K} K+\bar{q}_{T} T\right], \text { and } \\
& 0=r^{*} \bar{q}_{i}-\bar{g}_{i}, \quad(i=R, K, T) .
\end{aligned}
$$

Differentiating this system totally, we get

$$
\mathbf{h d R}=\mathbf{Q d \overline { y }} \text {, where } \mathbf{h}=\left[\begin{array}{c}
-\overline{\mathrm{g}}_{\mathrm{R}}-\overline{\mathrm{g}}_{\mathrm{p}_{\mathrm{N}}} \bar{\Phi}_{\mathrm{R}} \\
\beta \overline{\mathrm{q}}_{\mathrm{R}} \\
\overline{\mathrm{g}}_{\mathrm{RR}}+\overline{\mathrm{g}}_{\mathrm{R}_{\mathrm{N}}} \bar{\Phi}_{\mathrm{R}} \\
\overline{\mathrm{g}}_{\mathrm{KR}}+\overline{\mathrm{g}}_{\mathrm{K}_{\mathrm{p}_{\mathrm{N}}}} \overline{\boldsymbol{\Phi}}_{\mathrm{R}} \\
\overline{\mathrm{g}}_{\mathrm{TR}}+\overline{\mathrm{g}}_{\mathrm{T}_{\mathrm{N}}} \bar{\Phi}_{\mathrm{R}}
\end{array}\right] \text {, }
$$

which, upon using Cramer's rule, gives us

$$
\begin{aligned}
& \frac{d \overline{\mathrm{Z}}}{\mathrm{dR}}=\frac{\mathrm{r}^{* 3} \beta}{\operatorname{det}(\mathbf{Q})}\left(\mathrm{R} \overline{\mathrm{g}}_{\mathrm{RR}}+\mathrm{K} \overline{\mathrm{g}}_{\mathrm{KR}}+\mathrm{T} \overline{\mathrm{g}}_{\mathrm{TR}}\right) \\
& \quad+\frac{\mathrm{r}^{* 3} \beta \bar{\Phi}_{\mathrm{R}}}{\operatorname{det}(\mathbf{Q})}\left(-\overline{\mathrm{g}}_{\mathrm{p}_{\mathrm{N}}}+\mathrm{R} \overline{\mathrm{g}}_{\mathrm{Rp}_{\mathrm{N}}}+\mathrm{K} \overline{\mathrm{g}}_{\mathrm{Kp}_{\mathrm{N}}}+\mathrm{T} \overline{\mathrm{g}}_{\mathrm{T}_{\mathrm{p}_{\mathrm{N}}}}\right)
\end{aligned}
$$


Now note that $g_{R}$ is homogeneous of degree zero in $L, K, T$, and $R$, so that the first term on the right hand side of (22) is $\frac{-r^{*} \beta}{\operatorname{det}(Q)} L \bar{g}_{L R}$. Also, $g_{p N}$ is homogeneous of degree one in $L, K, T$, and $R$, so that the second term on the right hand side of (22) is $\frac{-r^{* 3} \beta}{\operatorname{det}(\mathbf{Q})} L \bar{\Phi}_{R} \bar{g}_{L_{P N}}$. Thus, (22) can be written as

$$
\frac{d \bar{Z}}{d R}=\frac{-r^{3} \beta}{\operatorname{det}(Q)} L \bar{g}_{L R}+\frac{-r^{*} \beta}{\operatorname{det}(\mathbf{Q})} L \bar{\Phi}_{R} \bar{g}_{L p_{N}}
$$

So the long run effect of a resource discovery on aggregate expenditure depends only on its effect on the wage rate in the steady state. The intuitive explanation for this result is very straightforward. In the model there is no intergenerational altruism, and agents are born with labour only. From (2) we can see that agents holding the country's assets at the time of the resource discovery bear all the costs (benefits) of a fall (rise) in the return to non-human factors into the infinite future. As these asset holders do not care about the welfare of future generations, they will consume all the discovered resources and also all the costs (benefits) that accrue to the country's non-human factors. This means that all these costs (benefits) to non-human factors are going to be eroded by the time a new steady state is reached, through changes in the country's net foreign asset position. Thus, the effect of a resource discovery on steady state aggregate expenditure depends only on its effect on the wage rate. This can also be seen by solving the equations in (20) for $\bar{Z}$, using the fact that $g$ is homogeneous of degree one in $L, K, R$, and $T$, which gives

$$
\overline{\mathrm{Z}}=\frac{\mathrm{L}}{\beta-\left(\mathrm{r}^{*}-\theta\right) \mathrm{r}^{*}} \overline{\mathrm{g}}_{\mathrm{L}}
$$

Thus, the steady state level of aggregate expenditure is proportional to the steady state level of the wage rate.

We call the first term on the right hand side of (23) the 'intergenerational effect' of the resource discovery on the long run aggregate expenditure, because, as we have seen already, $L \bar{g}_{L R}$ represents the shift in income from labour to the non-human factors at original goods prices: that is, a shift in purchasing power from future generations to current asset holders. The sign of this 'intergenerational effect' for the Benchmark model is negative for the following reason. In 
$S F M_{R M}$ an increase in the fixed factor, $R$, in the resource sector will reduce the amount of the mobile factor, capital, employed by the manufacturing sector. Now in SFM $M_{M}$ the fall in $K_{M}$ represents a fall in the specific factor in manufacturing. This will reduce the return to the mobile factor $L$. Therefore, in the Benchmark model $g_{L R}$ is negative. This means that the first term on the right hand side of (23) is negative.

We call the second term on the right hand side of (23) the 'supply effect' of the resource discovery on the long run aggregate expenditure, because the resource discovery affects the supply of the non-traded good. The change in the supply of the non-traded good changes $p_{N}$ and the wage rate, as given by $\bar{\Phi}_{R} \bar{g}_{L_{P N}}$. The sign of this 'supply effect' on the long run aggregate expenditure is negative for the following reason. In $\mathrm{SFM}_{\mathrm{NM}}$ an increase in the price of the non-traded good will increase the return to the mobile factor, $L$. Thus, $g_{L_{P N}}>0$. Also, as we have already argued $\Phi_{R}<0$. Thus, the second term on the right hand side of (23) is also negative.

Aggregate expenditure in the long run falls because of two reasons: firstly, the resource discovery shifts income from future generations to current asset holders $\left(\overline{\mathrm{g}}_{\mathrm{LR}}<0\right)$; secondly, the extraction of the discovered resources releases labour for the non-traded sector, encouraging the production of the non-traded good, which, without extra expenditure on non-traded goods, reduces the price of non-traded good, and, therefore, the wage rate $\left(\bar{\Phi}_{R} \bar{g}_{L P N}<0\right)$. In contrast, in other DD models, such as Corden and Neary (1982) and Neary and Purvis (1983), after the resorce discovery aggregate expenditure rises, just as in the short run in the present framework, because the discovered resources represent an increase in wealth.

Now, consider the effect of the resource discovery on the long run real exchange rate. From (17) we can see that

$$
\frac{d \bar{p}_{N}}{d R}=\bar{\Phi}_{Z} \frac{d \bar{Z}}{d R}+\bar{\Phi}_{R}
$$

Both terms on the right hand side of (25) are negative. Thus, the country experiences a long run real depreciation both because the extraction of the new resources shifts out the supply curve for non-traded goods $\left(\bar{\Phi}_{R}<0\right)$, and because in the long run aggregate expenditure falls.

The fall in long run aggregate expenditure could be so large that in the new steady state the country could have a smaller non-traded sector than it had originally. This contraction of the 
non-traded sector will then release some labour for the manufacturing sector, which may well cause a long run pro-industrialisation. To see this note that the output of the manufacturing sector is given by $\mathrm{g}_{\mathrm{p}_{\mathrm{M}}}$. Thus, the long run effect of a resource discovery on the output of the manufacturing sector is given by

$$
\begin{aligned}
\frac{d \bar{g}_{p_{M}}}{d R} & =\bar{g}_{p_{M} p_{N}} \frac{d \bar{p}_{N}}{d R}+\bar{g}_{p_{M} p_{N}} \\
& =\bar{g}_{p_{M} p_{N}}\left[\bar{\Phi}_{Z} \frac{d \bar{Z}}{d R}+\bar{\Phi}_{R}\right]+\bar{g}_{R p_{M}} .
\end{aligned}
$$

Now, $\overline{\mathrm{g}}_{\mathrm{PMPN}} \bar{\Phi}_{\mathrm{R}}+\overline{\mathrm{g}}_{\mathrm{PMPN}_{\mathrm{N}}}$ is the long run 'resource movement effect' of the resource discovery, to use the terminology of Corden and Neary (1982). This 'resource movement effect' is negative for the Benchmark model for the following reason. The increase in $R$ represents an increase in the factor specific to the resource sector in $\mathrm{SFM}_{\mathrm{RM}}$. This will cause a fall in, $\mathrm{K}_{\mathrm{M}}$, the mobile factor in the manufacturing sector. Now, the fall in $\mathrm{K}_{\mathrm{M}}$ also represents a fall in the factor specific to the manufacturing sector in $\mathrm{SFM}_{\mathrm{NM}}$, reducing $\mathrm{L}_{\mathrm{M}}$, the mobile factor employed in manufacturing. As both $K_{M}$ and $L_{M}$ fall at constant prices, $g_{R_{p}}$ is negative. Now note that the fall in $L_{M}$ implies an increase in $L_{N}$, and, therefore, an outward shift of the supply of the non-traded good. This outward shift of the supply of non-traded good will tend to reduce $p_{N}$, mitigating, but not reversing, the contraction of the manufacturing sector. This mitigation effect is given by $\overline{\mathrm{g}}_{\mathrm{PMPN}} \bar{\Phi}_{\mathrm{R}}$.

In (26), $\overline{\mathrm{g}}_{\mathrm{p}_{\mathrm{MPN}}} \bar{\Phi}_{\mathrm{Z}} \frac{\mathrm{d} \overline{\mathrm{Z}}}{\mathrm{dR}}$ represents the long run 'spending effect' of the resource discovery, again, using the terminology of Corden and Neary (1982). In other DD models $\frac{d Z}{d R}$ is positive, because the resource discovery increases wealth. This increased expenditure raises the demand for the non-traded good, causing further expansion of the non-traded sector, and further contraction of the manufacturing sector. However, in the present model, in the long run aggregate expenditure falls, reducing the demand for the non-traded sector. This fall in the demand for the non-traded good could be so large that in the long run the non-traded sector will contract, which may well release enough factors for the manufacturing sector to cause a pro-industrialisation. Thus, in the long run the country could experience both pro-industrialisation and real depreciation.

It is instructive to contrast our results so far with those from other DD models. In the simplest DD models the resource sector is completely independent of the rest of the economy, 
so that $\Phi_{R}=0$. Also, in standard DD models after the resource discovery aggregate expenditure rises, raising the demand for the non-traded good, as the resource discovery increases wealth. Thus, in the simplest DD model after the resource discovery the country unambiguously experiences a real appreciation. This raises the output of the non-traded sector at the expense of the manufacturing sector. Thus, the country experiences both real appreciation and deindustrialisation. However, this need not be the case if the resource sector is not an enclave. For example, in Neary and Purvis the production structure is identical to ours, except that the nontraded sector uses labour only. In that case after the resource discovery the resource sector draws capital from the manufacturing sector, causing the latter sector to release some labour for the non-traded sector. This raises the supply of the non-traded good. Thus, in Neary and Purvis, even though the demand for the non-traded sector rises, the country may still experience a real depreciation after the resource discovery, if the supply of the non-traded sector rises by a sufficiently large amount. Therefore, with the production structure of Neary and Purvis the country may experience real depreciation and de-industrialisation. On the other hand, in the model that Corden and Neary use in Section III of their paper, a resource discovery may lead to real appreciation and pro-industrialisation. In their production structure, Corden and Neary assume that only labour is used in the extraction of natural resources. Also, the non-traded and manufacturing sectors form a miniature Heckscher-Ohlin model with labour and capital mobile between the two sectors. A resource discovery will draw labour from this miniature Heckscher-Ohlin model and, by the Rybczynski (1955) effect, increase the supply of the maufacturing sector and reduce the supply of the non-traded sector, assuming that the non-traded sector is the relatively labour intensive sector. Thus, in the model used by Corden and Neary if the demand for the non-traded good does not increase by a large amount the country may experience pro-industrialisation and real appreciation. However, as pointed out by Neary and van Wijnbergen (1986, footnote 24), conventional DD models do not predict the possibility in our model of both real depreciation and pro-industrialisation due to a resource discovery.

Now consider the dynamic adjustment of the model. During the adjustment period the economy will move along the stable manifold given by the equations in (19). The dynamic paths of $B$ and $Z$ are shown in Figures (10) and (11), respectively. After the resource discovery, at time 0 , there will be a sharp increase in aggregate expenditure, as agents alive at the time of the dis- 
covery try to consume all the discovered resources. Thus, over time B will fall. This fall in the country's net foreign asset position will require aggregate expenditure to fall in order for the country to be able to pay the interest on the increased debt. Over time, therefore, $Z$ will be falling. If the extraction of resources is capital intensive, the amount of debt that is accumulated will be so large that in the new steady state aggregate expenditure would have to be smaller than it was originally.

The dynamic adjustment of the real exchange rate is shown in Figure (12). The increase in $\mathrm{R}$ shifts out the supply of the non-traded good, while the increased expenditure at the time of the discovery shifts out the demand for the non-traded good. Which one of these shifts is the larger will determine what happens to $p_{N}$ at time $0 . p_{N}$ is very likely to rise at time 0 , as in the conventional DD models. But over time, as aggregate expenditure falls the demand for the non-traded good falls, which reduces $p_{N}$. In the new steady state $p_{N}$ will be smaller than it was originally, if the extraction of resources is capital intensive.

The dynamics of the output of the manufacturing sector is shown in Figure (13). At time 0 there is a sharp fall in the output of that sector. This is because the extraction of the discovered resources reduces the amount of capital in manufacturing; and also because after the discovery there is a sharp rise in the demand for the non-traded good, causing the non-traded sector to draw labour from the manufacturing sector. Over time, as the demand for the non-traded good falls, the output of the manufacturing sector will rise. If the demand for the non-traded good falls by a sufficiently large amount, the steady state output of the manufacturing sector will be larger than it was originally. Therefore, in the short run the economy is likely to experience both real appreciation and de-industrialisation, as in conventional DD models. However, over time, as the discovered resources are consumed, $\mathrm{p}_{\mathrm{N}}$ will fall and the output of the manufacturing sector will rise, and in the new steady state the country may experience both real depreciation and proindustrialisation.

We conclude this section by comparing the results which we obtained by incorporating the Benchmark model into Blanchard's OLG framework with the results we would have obtained by incorporating other DD models into Blanchard's framework. First consider the production structure in Neary and Purvis (1983). There, as only labour is used in the non-traded sector, the wage rate is proportional to the price of the non-traded good, and so a resource discovery cannot 
change the wage rate at constant prices. Thus, the 'intergenerational effect' in (23) will be zero. The 'supply effect' in (23), on the other hand, will sill be negative, so that in the long run aggregate expenditure will fall. The dynamics of the system will be very similar to the dynamics of the system with the Benchmark model, except that in the long run the output of the non-traded sector will return to its original level. The reason for this is as follows. From (24) and the fact that the instantaneous utility function is logarithmic, we know that the long run equilibrium demand for the non-traded good is proportional to the real wage in the non-traded sector. But, as we have already seen, in the the production structure of Neary and Purvis the real wage in the non-traded sector is fixed. Thus, the long run demand function in that case will be vertical. The possibility of both real depreciation and pro-industrialisation will, therefore, be removed.

Now consider the dynamics of the system with the production structure that Corden and Neary (1982) use in Section III of their paper. There, at constant prices, the miniature Heckscher-Ohlin model formed by the non-traded and manufacturing sectors will determine the wage rate. Thus, at constant prices the resource discovery cannot change the wage rate, and the 'intergenerational effect' in (23) will be zero. The 'supply effect' in (23), on the other hand, will be positive. This is because the non-traded sector is relatively labour intensive, and the resource discovery, by drawing labour from the miniature Heckscher-Ohlin model, reduces the supply of the non-traded good, raising its price, and, by the Stolper Samuelson (1941) effect, the long run wage rate. Thus, in that case in the long run aggregate expenditure will rise. The economy will experience real appreciation in the long run, both because aggregate expenditure rises and because the supply of the non-traded good falls. Moreover, the rise in the price of the non-traded good, by the Stolper Samuelson effect, raises the real wage in the non-traded sector. This means that the long run output of the non-traded sector will rise, because, as we have seen already, the long run output of the non-traded sector is proportional to the long run real wage in that sector. The country will experience pro-industrialistion in the long run, if the supply of the non-traded sector does not rise by a large amount. However, note that if the resource sector uses capital instead of labour then the resource discovery will shift down the supply of the non-traded good. Then, in the long run the country will experience a real depreciation. The output of the nontraded sector will then be smaller than it was originally, because, by the Stolper Samuelson effect, 
the fall in $p_{N}$ will reduce the real wage in the non-traded sector. Thus, the possibility of obtaining both real depreciation and pro-industrialisation in the long run emerges in that case.

\section{Conclusions}

Some developing countries are currently suffering from the large scale borrowing that they undertook after their discoveries of natural resources. The amount of debt accumulated by these countries is so large that they are forced to undergo austerity measures to be able to pay the interest on their debts. In this paper we have viewed this as an intergenerational problem. We have shown that if the extraction of natural resources is capital intensive, then a resource discovery will shift income away from labour. This will benefit the asset holders alive at the time of the discovery, who will incur such a large debt that, in order to be able to pay the interest on the debt, aggregate expenditure in the new steady state would have to be smaller than it was originally. This will cause a long run real depreciation, and may lead to a contraction of the nontraded sector. This may then release factors for the manufacturing sector to cause a pro-industrialisation as well.

Developing countries in general seem to have incurred too much debt in the 1970's. Most of the borrowing was used to satisfy domestic consumption or to finance mostly short term investment projects. It is rather difficult to account for such large scale borrowing in terms of an infinitely lived representative agent. Such heavy borrowing could be regarded as an intergenerational problem. In the 1970's Western banks were willing to lend large amounts to developing countries at low interest rates. These countries, therefore, were able to borrow extensively against their potential. This could be seen as one reason why these countries now seem to have consumed part of their potential.

\section{Appendix 1}

In this appendix we show that the matrix $\mathbf{Q}$ has four positive and one negative eigenvalues. Let $\zeta$ be the eigenvalues, and let I be the identity matrix. Then The eigenvalues of $Q$ will be the roots of $\operatorname{det}(\mathbf{Q}-\zeta \mathbf{I})=0$. Now, 


$$
\operatorname{det}(\mathbf{Q}-\zeta \mathrm{I})=\mathrm{r}\left[(\mathrm{r}-\theta) \mathrm{r}^{3}-\beta \Phi_{Z} \mathrm{r}^{2}\left(\mathrm{~g}_{\mathrm{Rp}_{\mathrm{N}}} \mathrm{R}+\mathrm{g}_{\mathrm{K}_{\mathrm{N}}} \mathrm{K}+\mathrm{g}_{\mathrm{T}_{\mathrm{N}}} \mathrm{T}\right)\right]+\beta \mathrm{r}^{3}\left(\mathrm{~g}_{\mathrm{p}_{\mathrm{N}}} \Phi_{Z}-1\right),(\mathrm{A} .1)
$$

where $r=r^{*}-\zeta$. Now, using the fact that $g_{p N}$ is homogeneous of degree one in $L, K, T$, and $R$, it is very easy to show that the right hand side of (A.1) is, in fact,

$$
\left(\mathrm{r}^{*}-\zeta\right)^{3}\left\{\zeta^{2}-\zeta\left(\theta-2 \mathrm{r}^{*}\right)+\left[\mathrm{r}^{*}\left(\mathrm{r}^{*}-\theta\right)+\operatorname{Lg}_{\mathrm{Lp}_{\mathrm{N}}} \Phi_{\mathrm{Z}} \beta-\beta\right]\right\}
$$

Thus, $\left(r^{*}-\zeta\right)^{3}=0$ gives us three positive eigenvalues. The positive root of

$$
\zeta^{2}-\zeta\left(\theta-2 r^{*}\right)+\left[\mathrm{r}^{*}\left(\mathrm{r}^{*}-\theta\right)+\mathrm{Lg}_{\mathrm{Lp}_{\mathrm{N}}} \Phi_{\mathrm{Z}} \beta-\beta\right]=0
$$

gives us the fourth positive eigenvalue, while its negative root gives us the only negative eigenvalue. Note that this quadratic equation will have one positive and one negative root if and only if $\left[r^{*}\left(r^{*}-\theta\right)+\operatorname{Lg}_{L P N} \Phi_{Z} \beta-\beta\right]<0$, which is the condition for saddle point stability of the dynamic system in (18) around the steady state.

\section{Appendix 2. The Benchmark Model}

In this appendix we explore the main properties of the Benchmark model, and show that in that model in the long run the economy is likely to experience both real depreciation and pro-industrialisation.

Although we do not change notation, all the variables in this appendix are logarithms of the corresponding variables in the text.

As the resource and manufacturing sectors form a miniature specific factors model with $\mathbf{R}$ and $L_{M}$ as the specific factors, and $K$ as the mobile factor, the demands for capital by these industries could be written as

$$
\begin{aligned}
& K_{R}=\epsilon_{R} R-\gamma_{R}\left(r_{K}-p_{R}\right), \text { and } \\
& K_{M}=\epsilon_{M} L_{M}-\gamma_{M}\left(r_{K}-p_{M}\right),
\end{aligned}
$$


where $r_{K}$ is the logarithm of the return to capital, and $p_{R}$ and $p_{M}$ are the logarithms of the prices of the outputs of the resource and the manufacturing sectors, respectively, both of which we set to zero from now on.

Now, the market clearing condition for capital requires

$$
\lambda_{\mathrm{KR}} \mathrm{K}_{\mathrm{R}}+\lambda_{\mathrm{KM}} \mathrm{K}_{\mathrm{M}}=0 \text {, }
$$

where $\lambda_{i j}$ is the proportion of factor $i$ used in industry $j$.

Substituting for $K_{R}$ and $K_{M}$ from (A.2) and (A.3) into (A.4) and solving for $r_{K}$, we get

$$
r_{K}=\frac{\lambda_{K R} \epsilon_{R}}{\lambda_{K R} \gamma_{R}+\lambda_{K M} \gamma_{M}} R+\frac{\lambda_{K M} \epsilon_{M}}{\lambda_{K R} \gamma_{R}+\lambda_{K M} \gamma_{M}} L_{M}
$$

Substituting for $r_{K}$ from (A.5) into (A.3), we get

$$
K_{M}=\epsilon_{M} L_{M}-\frac{\gamma_{M} \lambda_{K R} \epsilon_{R}}{\lambda_{K R} \gamma_{R}+\lambda_{K M} \gamma_{M}} R-\frac{\gamma_{M} \lambda_{K M} \epsilon_{M}}{\lambda_{K R} \gamma_{R}+\lambda_{K M} \gamma_{M}} L_{M}
$$

This gives us the RR schedule in Figure (5), which shows the combinations of $K_{M}$ and $L_{M}$ that are consistent with equilibrium in the market for capital. $R R$ is positively sloping, because an increase in $L_{M}$ (the factor specific to the manufacturing sector) increases the amount of the mobile factor in manufacturing. 6

Now consider the market for labour. As the non-traded and manufacturing sectors form a miniature specific factors model with $T$ and $K_{M}$ as the specific factors and labour as the mobile factor, the demands for labour by these industries could be written as

$$
\begin{aligned}
& \mathrm{L}_{M}=\eta_{M} K_{M}-\delta_{M} w, \text { and } \\
& L_{N}=\eta_{N} T-\delta_{N}\left(w-p_{N}\right),
\end{aligned}
$$

where $w$ is the logarithm of the wage rate.

Market clearing in the market for labour requires

6 See Jones (1971) for the main properties of the Specific factors model, all of which are taken here as given. 


$$
\lambda_{L M} L_{M}+\lambda_{L N} L_{N}=0
$$

From (A.7), (A.8), and (A.9) we can derive the combinations of $K_{M}$ and $L_{M}$ that are consistent with equilibrium in the market for labour. This is shown as the NN schedule in Figure (5), and is given by

$$
\begin{aligned}
\mathrm{L}_{\mathrm{M}}=\eta_{\mathrm{M}} \mathrm{K}_{\mathrm{M}}-\frac{\delta_{M} \lambda_{\mathrm{LN}} \eta_{\mathrm{N}}}{\lambda_{\mathrm{LN}} \delta_{\mathrm{N}}+\lambda_{\mathrm{LM}} \delta_{\mathrm{M}}} \mathrm{T} & -\frac{\delta_{M} \lambda_{\mathrm{LM}} \eta_{\mathrm{M}}}{\lambda_{\mathrm{LN}} \delta_{\mathrm{N}}+\lambda_{\mathrm{LM}} \delta_{M}} \mathrm{~K}_{\mathrm{M}} \\
& -\frac{\delta_{M} \lambda_{\mathrm{LN}} \delta_{\mathrm{N}}}{\lambda_{\mathrm{LN}} \delta_{\mathrm{N}}+\lambda_{\mathrm{LM}} \delta_{M}} \mathrm{p}_{\mathrm{N}}
\end{aligned}
$$

The NN schedule in Figure (5) is upward sloping, because an increase in $\mathrm{K}_{\mathrm{M}}$ (the factor specific to the manufacturing sector) causes an increase in $L_{M}$ (the mobile factor employed by the manufacturing sector).

Note that for stability the NN schedule should be steeper than the RR schedule. To see this suppose we start from a point on the $R R$ schedule and reduce $L_{M}$ (the fixed factor in manufacturing in $S F M_{R M}$ ). This will reduce $K_{M}$ (the amount of mobile factor in manufacturing). So at any point below RR $K_{M}$ is rising, and at any point above it $K_{M}$ is falling. Now, starting from a point on NN, consider a fall in $K_{M}$ (the fixed factor in manufacturing in $S F M_{N M}$ ). Then, $L_{M}$ will fall. So at any point to the right of $N N L_{M}$ is falling, and at any point to the left of it $L_{M}$ is rising. The model is globally stable if $\mathrm{NN}$ is steeper than RR.

In Figure (5) the original equilibrium is at A. An increase in R, as can be seen from (A.6), shifts the RR schedule to the right, reducing $L_{M}$ and $K_{M}$. This reduces the output of the manufacturing sector, establishing $g_{R_{p}}<0$. The fall in $K_{M}$ represents a fall in the specific factor to manufacturing in $S F M_{N M}$. Hence, the wage rate must fall at constant $\mathrm{p}_{\mathrm{N}}$, establishing $\mathrm{g}_{L_{\mathrm{R}}}<0$. Also, note that the fall in $L_{M}$ will increase the output of the non-traded sector at constant $p_{N}$.

Now suppose $\mathrm{p}_{\mathrm{N}}$ rises. As can be seen from (A.10), this shifts the NN schedule to the left, reducing $\mathrm{K}_{M}$ and $\mathrm{L}_{\mathrm{M}}$. This will reduce the output of the manufacturing sector, establishing $\mathrm{g}_{\mathrm{P}_{\mathrm{MPN}}}<0$. The fall in $\mathrm{K}_{\mathrm{M}}$ will be accompanied by a rise in $\mathrm{K}_{\mathrm{R}}$. Therefore, in the new equilibrium the marginal productivity of capital in the resource sector must be lower. Thus, in the new equilibrium the return to capital must be lower. Now, the zero profit condition in the manufacturing sector requires a rise in the wage rate to accompany this fall in the return to capital. 
Thus, $g_{L_{p N}}>0$. The fall in $L_{M}$ is accompanied by an increase in $L_{N}$. With $T$ fixed, this increase in $L_{N}$ means that the real wage in the non-traded sector must have fallen. Also, the increase in $L_{N}$ means that the output of the non-traded sector must have increased.

Thus, we can write the supply of the non-traded good in logarithms as

$$
S^{N}=\sigma_{R} R+\sigma_{T} T+\sigma_{\mathrm{P}_{N}} \mathrm{P}_{N} \text {, where } \sigma_{i}>0 \forall i
$$

As the instantaneous utility function is logarithmic, we can write the demand function for the non-traded good in logarithms for a given $\mathrm{Z}$ as

$$
D^{N}=Z-P_{N}
$$

Now, from (A.11) and (A.12), and the market clearing condition $S^{N}=D^{N}$, we can see that $\left.\frac{d p_{N}}{d R}\right|_{Z}>0$ and $\left.\frac{d p_{N}}{d Z}\right|_{R}<0$, establishing the signs of the derivatives of $\Phi($.$) in (17).$

Finally, consider the likelihood of both real depreciation and pro-industrialisation in the long run. From (24) we can see that in the long run $\mathrm{Z}$ is proportional to w. Confining the analysis to the long run only from now on, we can write the long run demand for the non-traded goods as

$$
\vec{D}^{N}=w-p_{N}
$$

Now, from the foregoing comparative static results we know that when all goods prices are parametric $w$ varies positively with $p_{N}$ and negatively with $R$. Thus, we can write the semi-reduced form equation for $w$ as

$$
w=-\psi_{R} R+\psi_{T} T+\psi_{p_{N}} p_{N} \text {, where } \psi_{i}>0 \forall i
$$

As shown above, when $\mathrm{p}_{\mathrm{N}}$ rises the real wage in the non-traded sector falls. This means that $\psi_{\mathrm{PN}}<1$.

Substituting for $w$ from (A.14) into (A.13) we get the long run demand function for the non-traded good as

$$
\overline{\mathrm{D}}^{\mathrm{N}}=-\psi_{\mathrm{R}} \mathrm{R}+\psi_{\mathrm{T}} \mathrm{T}+\left(\psi_{\mathrm{p}_{\mathrm{N}}}-1\right) \mathrm{p}_{\mathrm{N}}
$$


The effect of an increase in $R$ on long run output of the non-traded good is, therefore,

$$
\frac{d \bar{D}^{N}}{d R}=-\psi_{R}+\left(\psi_{p_{N}}-1\right) \frac{d \bar{p}}{d R}
$$

Now, from (25), $\frac{d \bar{p}}{d R}<0$. Thus, The first term on the right hand side of (A.16) is negative, while the second term is positive. So the output of the non-traded sector could fall in the long run. The reason for this is very simple. From (A.11), and (A.15) we can see that a resource discovery tends to shifts out the supply of the non-traded good but to shift in the long run demand for it. Thus, if the demand curve shifts in by a large amount then the output of the non-traded sector could fall. This will then mean an increase in $L_{M}$, which may well cause a pro-industrialisation in the long run.

\section{References}

Blanchard, O. (1985): “Debts, Deficits, and Finite Horizons”. Journal of Political Economy, 93, 223-247

Buiter, W.H. and D. D. Purvis (1983): "Oil, Disinflation and Export Competitiveness: a Model of the Dutch Disease", in J. Bhandari and B. Putman (eds.) Economic Interdependence and Flexible Exchange Rates, Cambridge. Mass. : M.I.T. Press.

Corden, W.M., and J.P. Neary (1982): "Booming Sectors and De-industrialisation in a Small Open Economy”. Economic Journal, 92 (December), 825-48

Diamond, P. A. (1965): "Natioanal Debt in a Neoclassical Growth Model". American Economic Review, 55, 1126-1150.

Dornbusch, R. (1976): “Expectations and Exchange Rate Dynamics". Journal of Political Economy, vol. 84,

Eastwood, R. K., and A. J. Venables (1982): "The Macroeconomic Implications of a Resource Discovery in an Open Economy". Economic Journal, 92, 285-99

Eaton, J. (1987): “A Dynamic Specific-Factors Model of Internatioal Trade”. Review of Economic Studies, LIV, 325-338 
Fried, J. (1980): “The Intrgeneratioal Distribution of Gains from Technical Change and from International Trade" Canadian Journal of Economics, 13, 65-81

Harberger, A. C. (1985): "Lessons for Debtor-Country Managers and Policymakers", in Smith, G. W. and J. T. Cuddington (eds.) International Debt and Developing Countries (IBRD, Washington, D.C., 236- 257.

Jones, R. W. (1971): "A Three Factor Model in Theory, Trade and History", in J. N. Bhagwati et al. (eds.): Trade, Balance of Payments and Growth: Essays in the Honour of C. P. Kindleberger, Amsterdam: North-Holland, pp. 3-21.

Matsuyama, K. (1988): "Terms of Trade, Factor Intensities and the Current Account in a LifeCycle Model". Review of Economic Studies, LV, 247-262

Neary, J.P. and D.D. Purvis (1982): "Real Adjustment and Exchange Rate Dynamics" in J. Frenkel (ed.): Exchange Rates and Internatioal Macroeconomics, Chicago: Chicago University Press.

Neary, J.P. and S. van Wijnbergen (1984): “Can an Oil Discovery Lead to a Recession?" Economic Journal, 94, 390-5.

Neary, J.P. and S. van Wijnbergen (1986): “Natural Resources and the Macroeconomy: a Theoretical Framework" in Neary, J.P. and S. van Wijnbergen (eds.) Natural Resources and the Macroeconomy, Basil Blackwell

Rybczynski, T.M. (1955): "Factor Endowment and Relative Commodity Prices", Economica, 22, 336-341.

Stolper, W. F., and Samuelson, P.A. (1941): "Protection and Real Wages", Review of Economic Studies, 9, 58-73.

van Wijnbergen, S. (1984a): “The Dutch Disease: A Disease After All?” Economic Journal, 94, 41-55.

van Wijnbergen, S. (1984b): "Inflation, Employment and the Dutch Disease in Oil Exporting Countries: a Short Run Disequilibrium analysis" Quarterly Journal of Economics, 99, 233-50. 
FIGURE 1

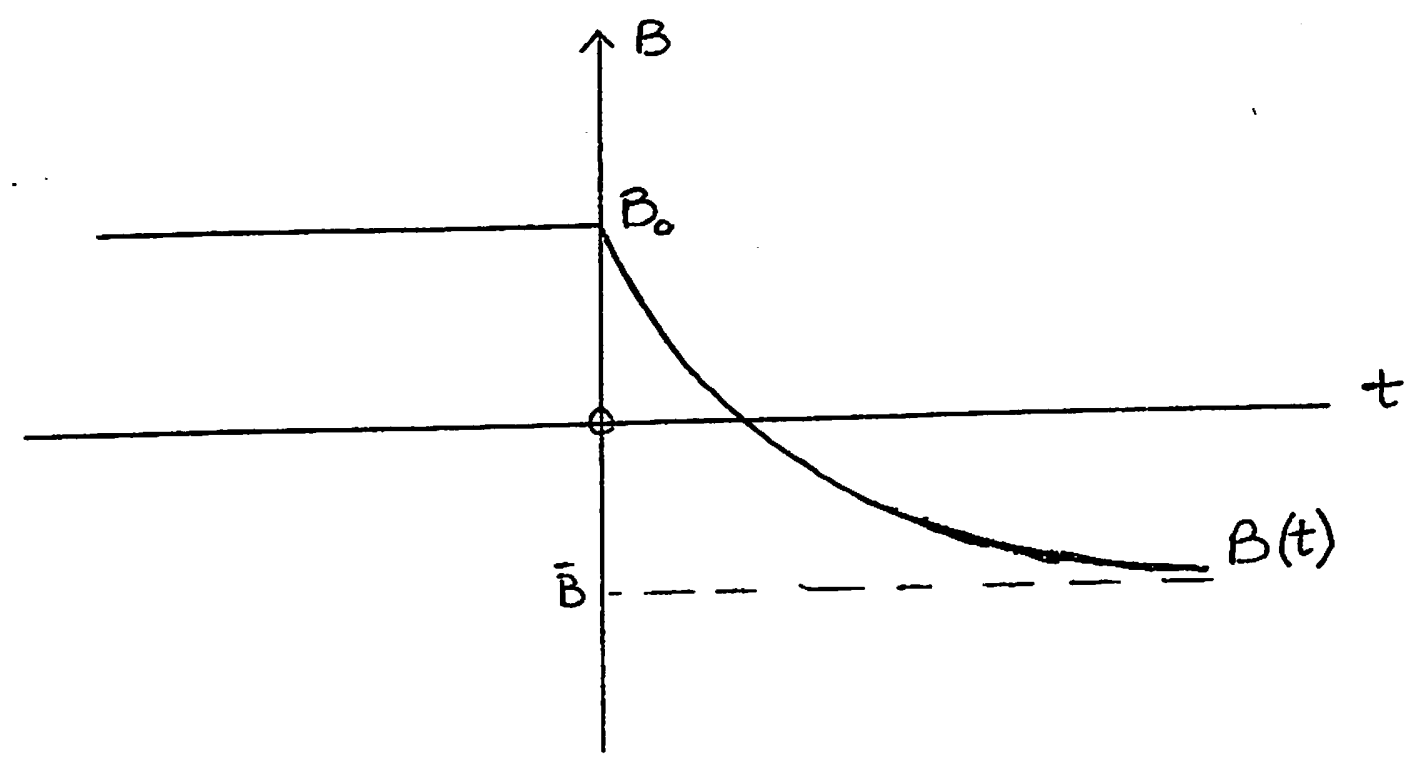

FIGURE 2

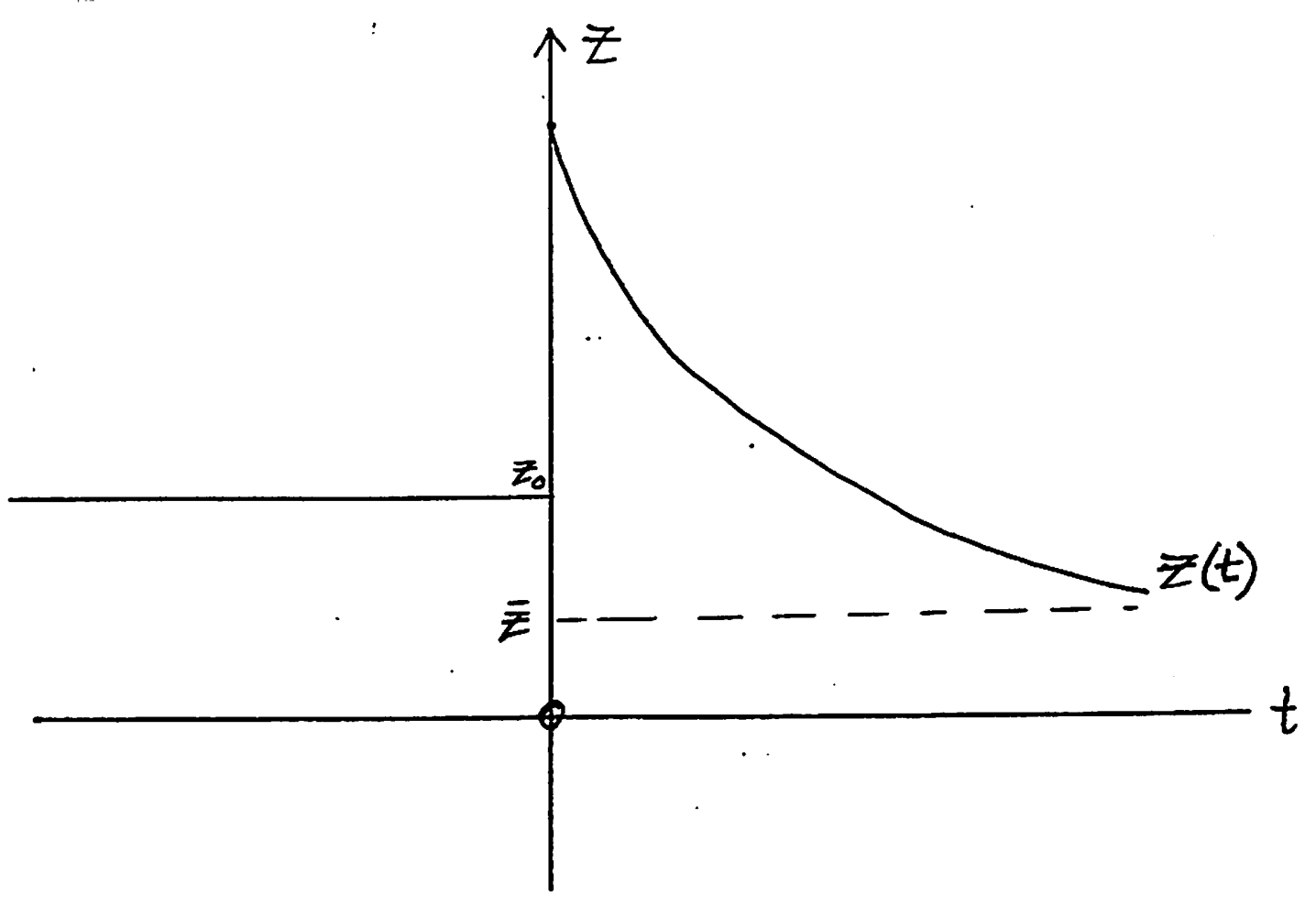


FIGURE 3

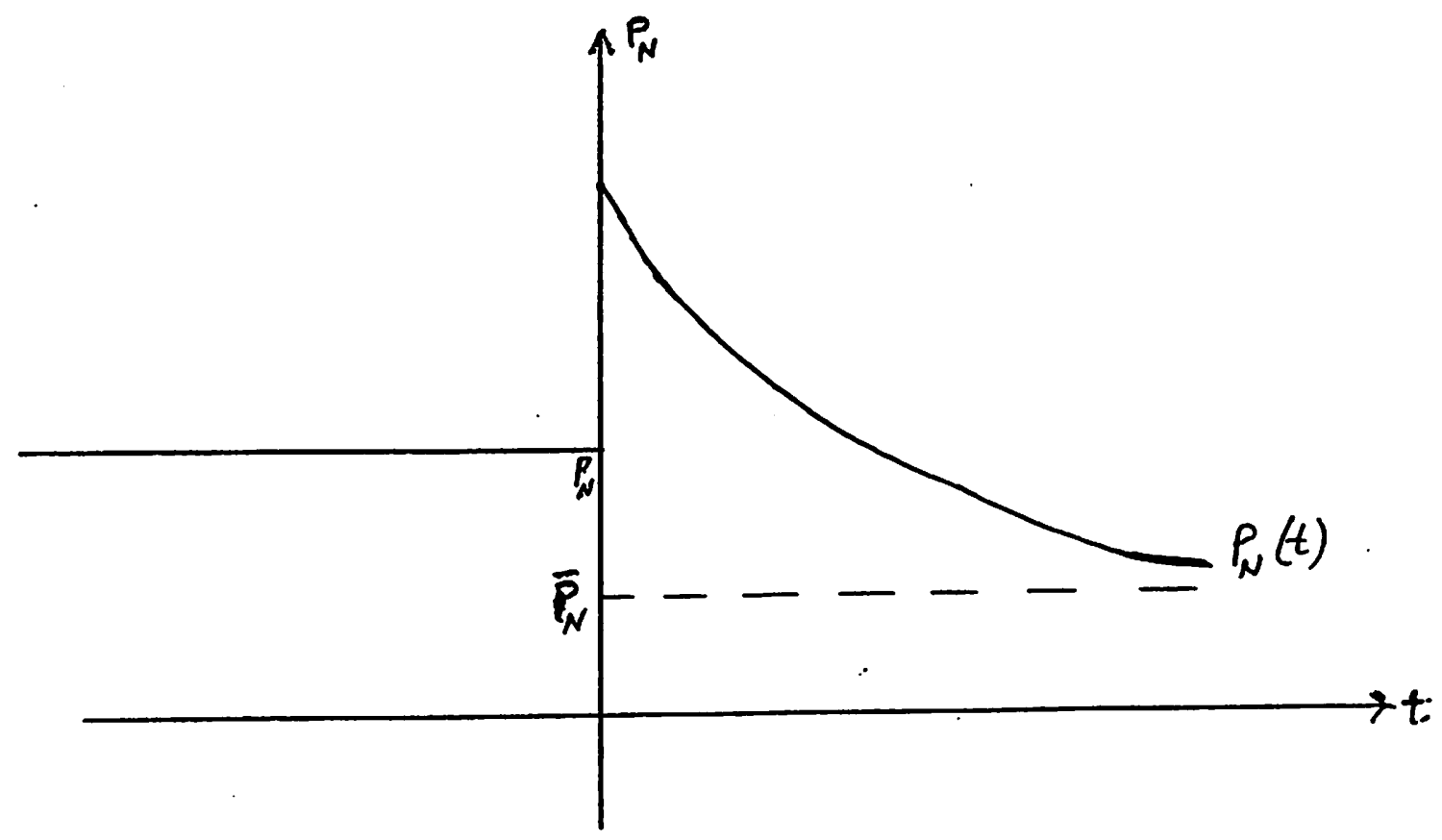

FIGURE 4

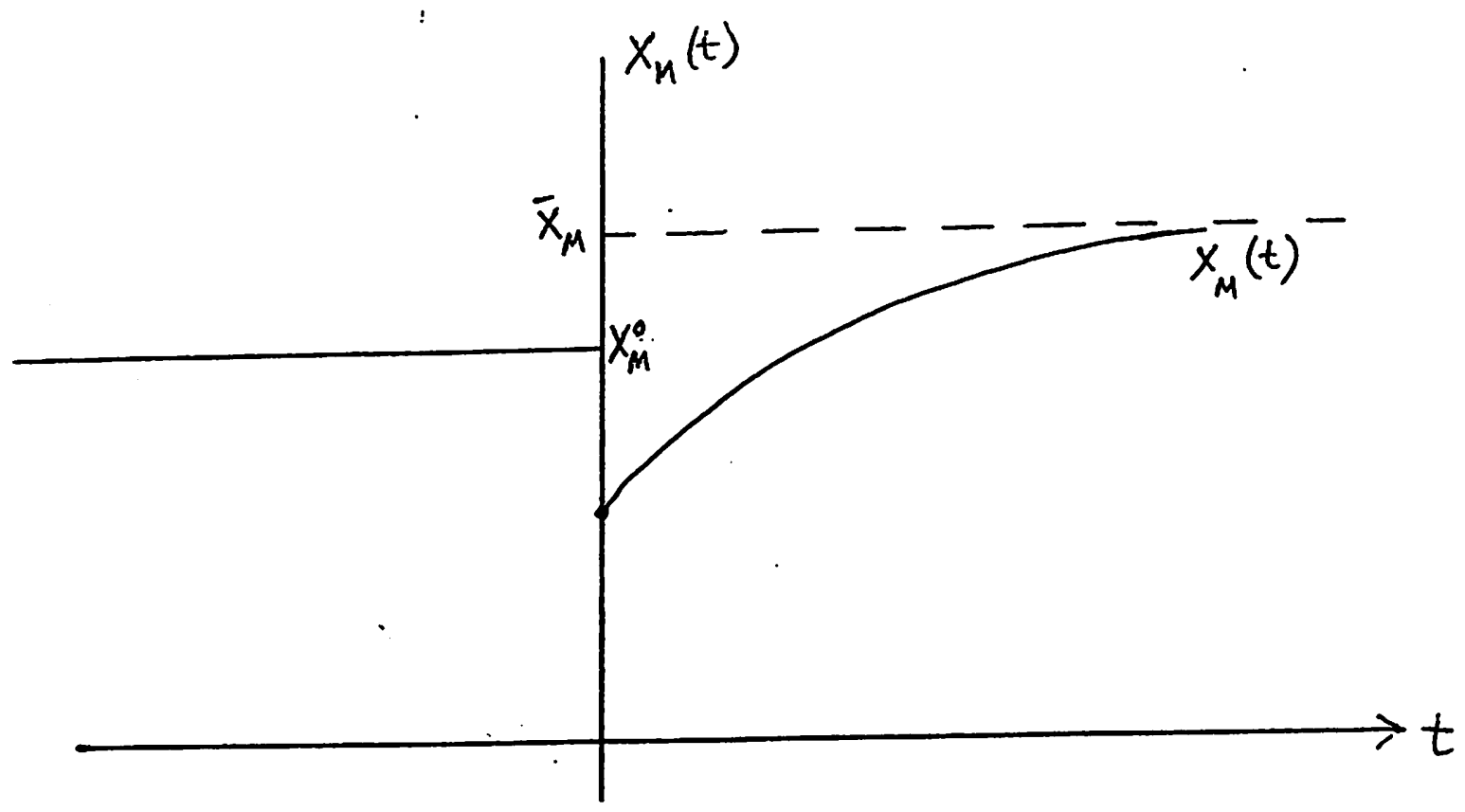


FIGURE 5 .

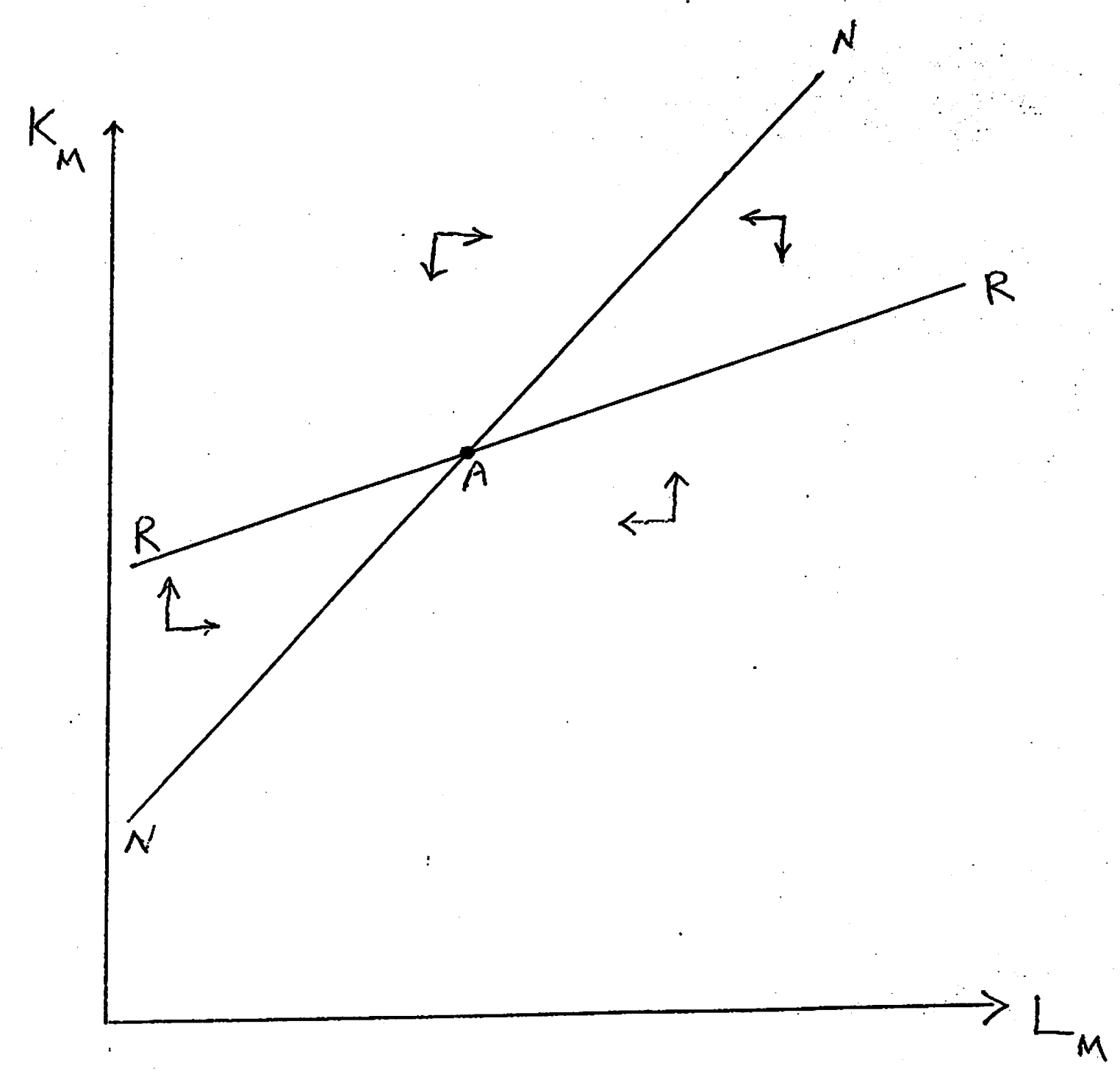

